\title{
Passive solar design in schools for the protection of the environment Greece: a case study
}

\author{
Agisilaos Economou ${ }^{1, *}$ \\ ${ }^{1}$ National Technical University of Athens, Athens, Greece \\ *Corresponding author. Tel: +03 9345386, Fax: +039345386, E-mail: aghs@mail.ntua.gr
}

\begin{abstract}
The survey focuses on the passive solar schools units that have been built to date in Greece. It investigates on the one hand the bioclimatic principles applied to several school units with regard both to the building shell and the layout of the schoolyard area, and on the other hand the energy saving schemes that have been introduced to reduce energy consumption. This investigation is followed by a comparison with conventional schools in order to assess the economic and environmental benefits that the implementation of passive solar design bring to Greek schools.

The present survey relies on statistical data collected from passive solar design and conventional school buildings taking into account, among others, energy consumption, school building plots and implemented bioclimatic principles. Furthermore, in order to collect information about various issues and the cost of these new school units, the survey relies on personal interviews with staff members of the School Building Organization which is responsible for the construction of these schools.

The survey has shown that passive solar design used in the building of schools in conjunction with the installation of electronic control equipment to reduce consumption and the use of renewable energy, achieves a larger degree of environmental protection.
\end{abstract}

Keywords: Passive solar design in schools, Save energy.

\section{Introduction}

In Greece, school buildings, according to past interventions for energy saving and protection are divided into neoclassical buildings of the interwar period until 1950, school buildings built prior to the application of the General Building Rules (GBR)(1950-1980), school buildings constructed under the new implementation of the (GBR) (1979) [1] until 1998 when new measures were taken and terms were set to improve energy efficiency of buildings [2]. After Directive 2002/91/EC [3] of the European Union for the energy performance of buildings new measures were taken to reduce energy consumption in buildings, more specifically law 3661 [4], the Regulation of Energy Efficiency of Buildings [5] and law 3855 [6] in accordance with the directives of the European Union for energy saving.

Initially, the proposals for interventions in school buildings (from 1950 to 1980) refer to the closure of open corridors, to the insulation of the roof, replacement of window and door frames, the addition of RES, ventilation cooling and shading. Thermal bridges reduction was added to school buildings from 1980 to 1998 [7]. The bioclimatic design in school buildings was implemented on a pilot basis. Generally, the measures applied were thermal insulation, green roofs, and minimization of northern openings exposure during the winter,. On the other hand, during the summer, the measures applied were the minimization of western openings, shading and cross ventilation. Other passive systems such as solar atriums, skylights, cooling chimneys and soil pipes, were implemented [8].

Take into account that most schools have been built before the year 2000, it is shown that heat losses are much larger than those of school buildings constructed after 2000, which have implemented more stringent requirements for insulation and appropriate choice of materials.

Especially from 2007 and onwards, all schools in Greece are built in accordance with the principles of bioclimatic design related to both the architectural design and the choice of 
location of the school. Also the extension of bioclimatic design in courtyards contributes more to the improvement of environmental conditions in schools and the better use of space and climate conditions.

In addition, the pilot application for the introduction of technology on energy saving systems in schools such as BMS systems, opens new horizons in energy saving.

Generally, the new design of schools, taking into account the bioclimatic principles both in the building shell and in the exterior space as well as energy-saving technologies in conjunction with the strictest standards for heat insulation, will contribute to good weather conditions with the minimum of energy consumption. The degree to which this new way of designing schools unit contributes to energy saving, will be analyzed below.

We note that the new standards for energy conservation should not be in conflict with bioclimatic design principles, but to complement them.

\section{Methodology}

First a reference to the policies implemented so far for the construction of schools in Greece is made. Next, the survey compares the fuel consumption between conventional schools and new schools with passive systems. Taking into account the thermal and climatic conditions in the region, the implementation or not of bioclimatic principles, an effort to estimate to which degree the use of passive solar systems can contribute to saving energy and protect the environment is made.

Thus, statistical data on the area and fuel consumption in selected schools are used in the survey. Also, the survey was supplemented with new data on the current policy for the construction of schools units. This information have been obtained through personal interviews of the directors of the School Building Organization, which is responsible for the construction of schools in Greece. The creation of maps is achieved by using data from Geographic Information Systems (GIS).

\section{Results}

The survey focused on schools units which are built according to the principles of bioclimatic design, as well as on conventional schools. Specifically, the research focused on the energy consumption for heating, taking into account the thermal, climatic conditions in the area and the buildings were designed.

From a survey made to the staff of the School Building Organization which are responsible for the construction of schools in Greece it is found that:

- Nowadays, the lack of suitable land in areas with increased urbanization, creates problems in the design of schools according to the principles of bioclimatic design.

- The old schools units need both maintenance and upgrading of heat insulation and sun protection.

- All schools built since 2007, and onwards follow the bioclimatic design principles, taking into account the location and orientation of the building. Techniques for sun protection, natural lighting, shading, natural ventilation (ventilation, traction phenomenon, solar chimney and cooling tower) and thermal insulation are applied. Green materials, wooden structures as well as green roofs and high planting are used (Fig. 1).

- Introduction of new insulating materials and automation programs for saving energy. 
- Expansion of the use of natural gas in schools units in order to save energy and reduce emission of pollutants.

- Exploitation of strong sunlight via the use of photovoltaic systems. Due to good weather conditions and sunshine, in Greece, the design of school buildings different from those of northern European Union countries with different climatic conditions.

- Introduction of geothermal energy for heating and cooling in special school units, which are constructed for children with special needs, requiring greater energy consumption.

- Introduction of the new regulation on the energy performance of buildings in school buildings in order to obtain an energy building certification.

\subsection{Schools units in Greece}

New passive solar building constructed from 2007 onwards in Greece are presented in the following map (Fig. 1).

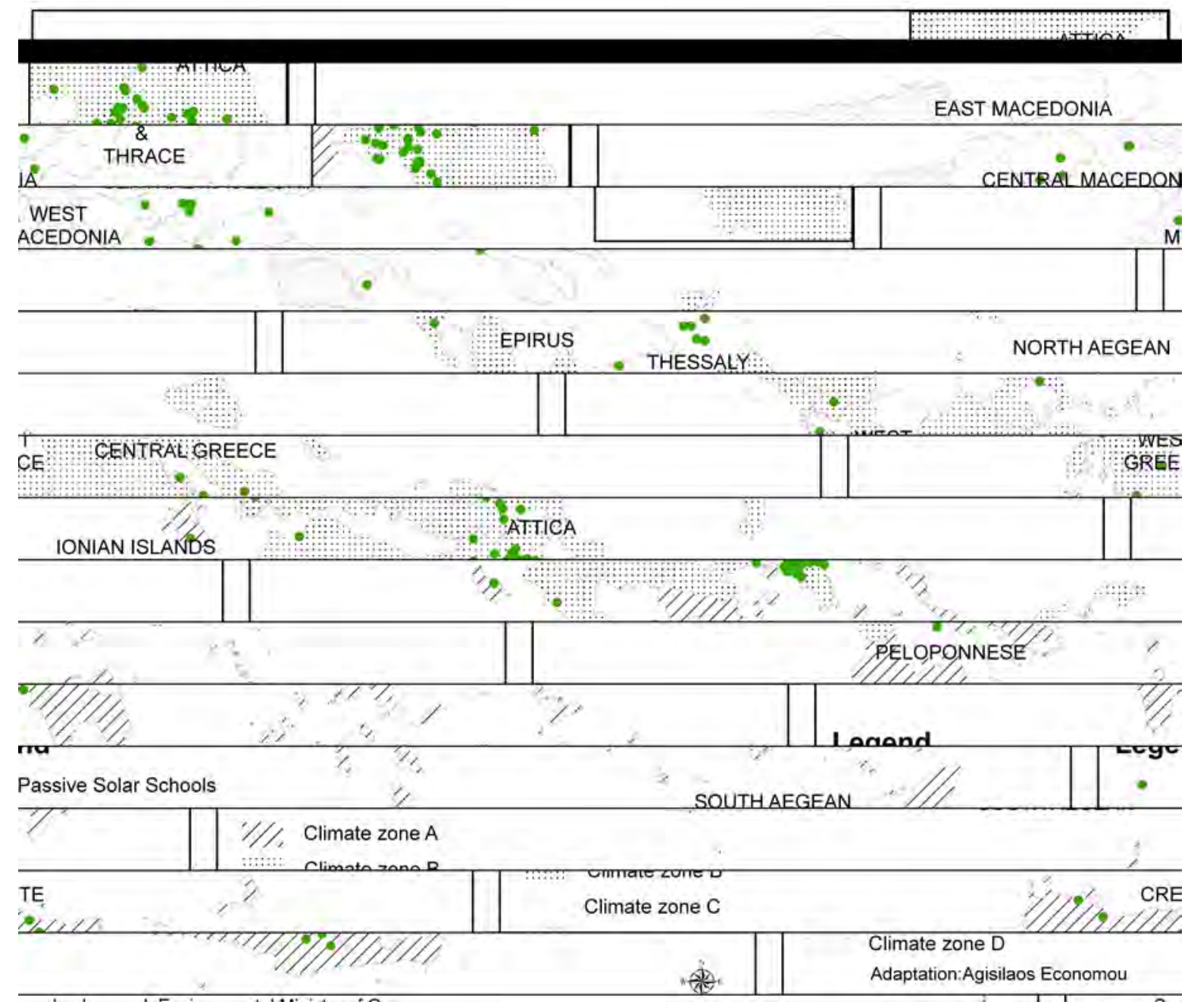

Fig. 1. Passive solar schools in Greece from 2007 up-today.

\subsection{Schools units in Athens}

As conventional schools, schools in Athens which are listed in the table below have been selected (Fig. 2), (Table 1). On the other hand, from the new modern schools the 6th Nursery school in Paleo Faliro, which is the first school designed with passive systems was selected. It features specific provisions for sun protection, shading, ventilation with carbon dioxide sensors to upgrade and clean the air, greenhouse and two green roofs.Also, it has lighting 
control systems which take into account the sunshine outside and for heating, natural gas is used. Also a photovoltaic systems has been installed on the school for electricity production.

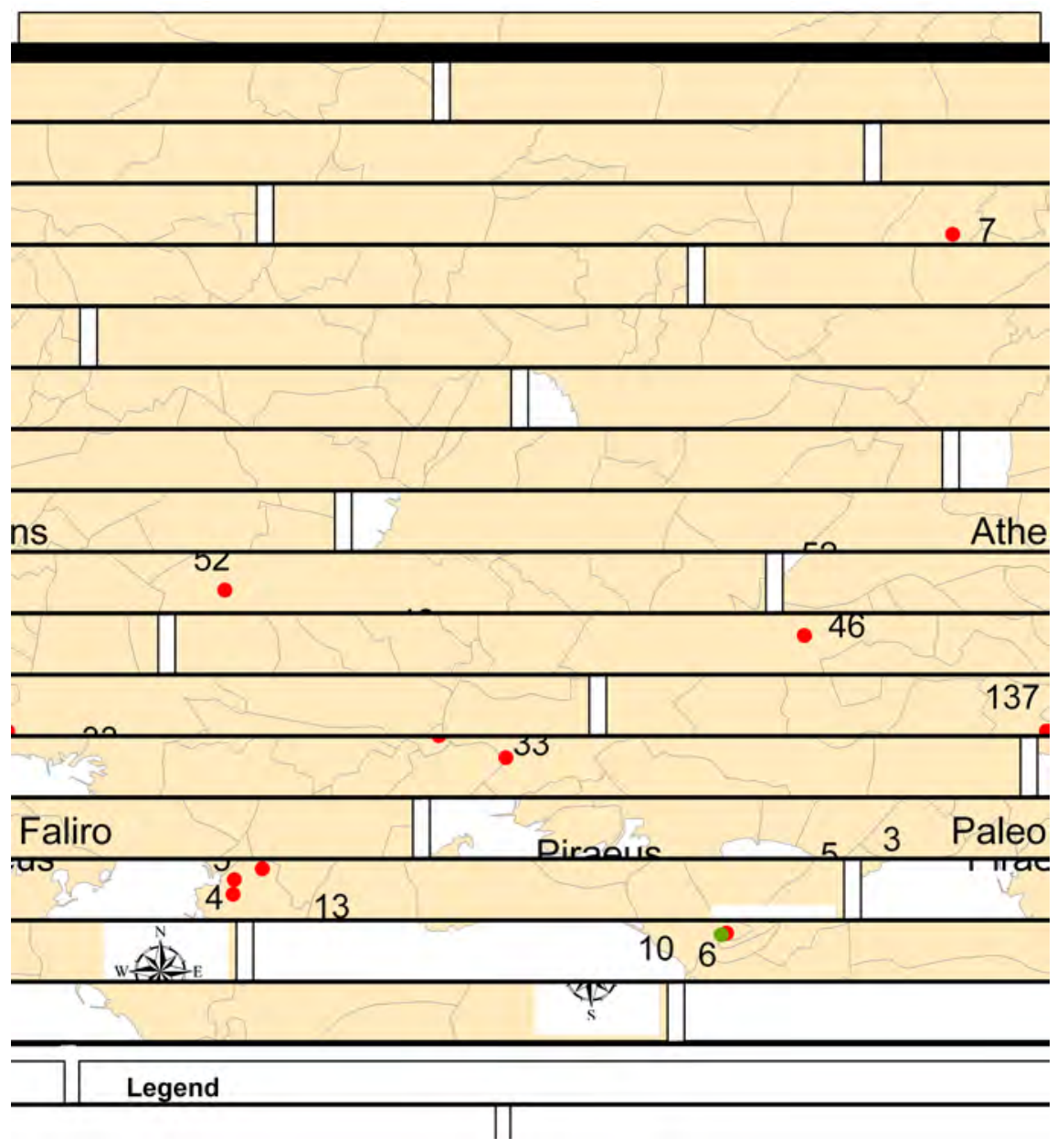

Fig. 2.Schools units in Athens

The survey found that in conventional school units there are different levels of consumption, depending on heat insulation and on the time period during which the boiler is operating for heating purposes.

In contrast in the 6st nursery school of Paleo Faliro (passive solar) a significant decrease in fuel consumption, compared to other schools in the same period was found.

Similar reductions were made to other schools in the past. For example, in the school unit of A. Kapon in Andros in 1989, which has an area of $513.5 \mathrm{~m}^{2}$ with Tromble walls and $10 \mathrm{~cm}$ polystyrene insulation, the consumption was $12.36 \mathrm{Kwh} / \mathrm{m}^{2}$. While in the school unit of I. Kalligeris in Rethymno in 1987, which has an area of $893.7 \mathrm{~m}^{2}$, through the use of greenhouses and shading, the consumption was at $6.73 \mathrm{Kwh} / \mathrm{m}^{2}$.[8]. In other school units systems for solar gain, solar terraces, double glazing and others have been implemented. 
Table 1. Use of natural gas for heating in school units in Athens during the period time 9/2009-8/2010 $[9,10]$

\begin{tabular}{llllll}
\hline Schools units & $\begin{array}{l}\text { Year of } \\
\text { constructi } \\
\text { on }\end{array}$ & $\begin{array}{l}\text { Total floor } \\
\text { area } \\
\text { ( }\end{array}$ & $\begin{array}{l}\text { Total } \\
\text { volume of } \\
\text { building }\end{array}$ & $\begin{array}{l}\text { Consumpt } \\
\text { ion of } \\
\text { natural } \\
\text { gas }(\mathbf{K w h})\end{array}$ & $\left(\mathbf{K w h} / \mathbf{m}^{\mathbf{2}}\right)$ \\
\hline 46 High School of Athens & 1917 & 2698.00 & 9421.00 & 70990.85 & 26.31 \\
\hline 52 High School of Athens & 1970 & 2714.45 & 9734.35 & 50091.29 & 18.45 \\
\hline 7 Secondary of Metamorfosi & 1980 & 1244.00 & 4552.00 & 62691.07 & 50.39 \\
\hline 33 High School of Athens & 1984 & 2451.07 & 12429.12 & 42235.80 & 17.23 \\
\hline 5 High School of Paleo Faliro & 1986 & 3835.80 & 7448.85 & 42012.18 & 10.95 \\
\hline 13 Secondary of Paleo Faliro & 1992 & 1896.24 & 7600.00 & 48663.39 & 25.66 \\
\hline 3 Nursery of Paleo Faliro & 1993 & 210.50 & 800.00 & 5444.56 & 25.86 \\
\hline 137 Secondary of Athens & 1993 & 1626.00 & 5962.00 & 36700.86 & 22.57 \\
\hline 10 Secondary of Paleo Faliro & 1995 & 1700.00 & 6652.00 & 38724.61 & 22.77 \\
\hline 4 High School of Paleo Faliro & 2000 & 3835.80 & 7448.85 & 21728.73 & 5.66 \\
\hline 6 Nursery of Paleo Faliro & 2005 & 600.20 & 2640.90 & 3063.00 & 5.10 \\
\hline
\end{tabular}

Also, the use of natural gas in the schools units has further reduced the emissions of $\mathrm{CO}_{2}$ in contrast to oil (Table 2)

Emission of $\mathrm{CO}_{2}$, natural gas $0.20 \mathrm{~kg} / \mathrm{kWh}$, diesel fuel oil $0.26 \mathrm{~kg} / \mathrm{kWh}$ ) [11]

\section{Discussion}

Fuel consumption for heating of school grounds, varies depending on:

The climatic conditions of each region: Based on heating degree days and altitude, we have four climatic zones. From the hottest to the coolest (Fig. 1).

Heating time: The duration of the heating season ranged from 60 days to the region of Crete and reaches 210 days in the areas of Macedonia and Thrace [5].

Heat insulation: The heat insulation of buildings and the way of construction such as the orientation of the building, insulation of walls, floors and roofs, thermal insulation materials used and the use of openings.

Also, many schools and big complexes are attached to the operation of one boiler, which means that the above operation of a school or a department requires the operation of the boiler for more time as a result of which school units are heated unnecessarily. 
Nowadays, in conventional schools interventions are made in order to increase the insulation during the winter and to ensure sun protection, ventilation and cooling during the summer months.

Table 2. Consumption in school units and emission of $\mathrm{CO}_{2}$

\section{Consumption of}

Schools units natural gas[10]

(Kwh)
Emission of $\mathrm{CO}_{2}$ (ton) (if we used natural gas) (ton)
Emission of $\mathrm{CO}_{2}$

( if we used oil )

(ton)

\begin{tabular}{lccc}
\hline 46 High School of Athens & 70990.85 & 14.19 & 18.45 \\
\hline 5 High School of Paleo Faliro & 50091.29 & 10.01 & 13.02 \\
\hline 7 Secondary of Metamorfosi & 62691.07 & 12.53 & 16.30 \\
\hline 33 High School of Athens & 42235.8 & 8.44 & 10.98 \\
\hline 5 High School of Paleo Faliro & 42012.18 & 8.40 & 10.92 \\
\hline 13 Secondary of Paleo Faliro & 48663.39 & 9.73 & 12.65 \\
\hline 3 Nursery of Paleo Faliro & 5444.56 & 1.08 & 1.41 \\
\hline 137 Secondary of Athens & 36700.86 & 7.34 & 10.06 \\
\hline 10 Secondary of Paleo Faliro & 38724.61 & 7.74 & 5.64 \\
\hline 4 High School of Paleo Faliro & 21728.73 & 4.34 & 0.79 \\
\hline 6 Nursery of Paleo Faliro & 3063 & 0.61 & \\
\hline
\end{tabular}

The above data shows (Table 1) that new schools planned in accordance with the principles of bioclimatic design and new energy saving measures, require less energy to operate than conventional schools.

In addition, the use of natural gas has reduced energy consumption due to the higher calorific value of gas compared to oil. Even the use of renewable energy sources in new school units it will contribute more to the protection of the environment.

\section{Conclusions}

New school units require less energy than conventional schools. An important role in energy consumption is played by the location of the school unit, thermal insulation as well as the use of passive solar systems. As it turned out, the implementation of new laws on heat insulation has increased significantly the reduction of energy consumption.

The survey showed that the existing conventional schools who consume large amounts of energy, are in need of improvement.

Also, the use of renewable energy sources such as photovoltaic systems, saves important natural resources, while the introduction of geothermal energy to schools, will reduce energy consumption even further. 
Conclusively, not only do passive solar schools contribute to energy consumption reduction, but they also contribute to the conservation of natural resources and the reduction greenhouse gases emissions to the atmosphere. Nowadays, new techniques applied in schools and new energy-saving systems create a new field of research in the forthcoming years.

\section{References}

[1] Official Journal of the Hellenic Republic, 362/D/07.04.1979, pp.3960-4035 http://www.et.gr/search_publication

[2] Official Journal of the Hellenic Republic, 880/B/19.08.1998, pp.10071-10077 http://www.et.gr/search_publication

[3] Commission of the European Communities, Directive 2002/91/EC of the European Parliament and of the Council of 16 December on the energy performance of buildings, OJ, L1/65, Brussels, 2003, pp. 1-7.

[4] Official Journal of the Hellenic Republic, 89/19.05.2008, pp.1371-1377 http://www.et.gr/search_publication

[5] Official Journal of the Hellenic Republic, 407/B/09.04.2010, pp.5333-5346 http://www.et.gr/search_publication

[6] Official Journal of the Hellenic Republic. 95/A/23.06.2010, pp.1955-1964 http://www.et.gr/search_publication

[7] Ministry of Environment Energy \& Climate Change/ Directorate of Urban Affairs and Housing - Center for Renewable Energy Sources (CRES), Action Plan for energy saving in residential sector "Energy 2001", 1995.

[8] E. Lazari, Center for Renewable Energy Sources (CRES), Bioclimatic Design in Greece: Energy efficiency and guidelines for implementation, Pikermi, 2002, pp.1-40.

[9] SBO (School Building Organization S.A.), Statistics Data Units 2007-2010, Athens, 2010.

[10] EPA, Provider of natural gas, Statistical Data on natural gas consumption in Attica buildings during the year 2009, Athens, 2009.

[11] Papanikas D., Natural Gas Technology, Media Guru, M.\&Fr. Papanika Editions,Vol I, 2nd edition, Athens, Greece 2007, pp.156-157. 